\title{
A System Identification-Based Damage-Detection Method for Gravity Dams
}

\author{
Masoud Mirtaheri $\mathbb{D},{ }^{1}$ Mojtaba Salkhordeh $\mathbb{D}$, ${ }^{1}$ and Masoud Mohammadgholiha $\mathbb{D}^{2}$ \\ ${ }^{1}$ Department of Civil and Environmental Engineering, K. N. Toosi University of Technology, Tehran, Iran \\ ${ }^{2}$ Department of Electrical, Electronic, and Information Engineering, University of Bologna, Bologna 40136, Italy \\ Correspondence should be addressed to Masoud Mirtaheri; mmirtaheri@kntu.ac.ir
}

Received 12 November 2020; Revised 27 January 2021; Accepted 19 February 2021; Published 26 February 2021

Academic Editor: Tzu-Kang Lin

Copyright ( $) 2021$ Masoud Mirtaheri et al. This is an open access article distributed under the Creative Commons Attribution License, which permits unrestricted use, distribution, and reproduction in any medium, provided the original work is properly cited.

\begin{abstract}
Dams are essential infrastructures as they provide a range of economic, environmental, and social benefits to the local populations. Damage in the body of these structures may lead to an irreparable disaster. This paper presents a cost-effective vibration-based framework to identify the dynamic properties and damage of the dams. To this end, four commonly occurred damage scenarios, including (1) damage in the neck of the dam, (2) damage in the toe of the structure, (3) simultaneous damage in the neck and the toe of the dam, and (4) damage in the lifting joints of the dam, are considered. The proposed method is based on processing the acceleration response of a gravity dam under ambient excitations. First, the random decrement technique (RDT) is applied to determine the free-vibration of the structure using the structural response. Then, a combined method based on Hilbert-Huang Transform (HHT) and Wavelet Transform (WT) is presented to obtain the dynamic properties of the structure. Next, the cubicspline technique is used to make the mode shapes differentiable. Finally, Continuous Wavelet Transform (CWT) is applied to the residual values of mode shape curvatures between intact and damaged structures to estimate the damage location. In order to evaluate the efficiency of the proposed method in field condition, $10 \%$ noise is added to the structural response. Results show promising accuracy in estimating the location of damage even when the structure is subjected to simultaneous damage in different locations.
\end{abstract}

\section{Introduction}

Civil engineering infrastructures provide the essential instruments for a community to have an immediate operation. These infrastructures include buildings, vehicular and pedestrian bridges, factories, transmission towers, and dams. Concrete dams provide economic benefits by supplying water for irrigation, energy for hydroelectricity generation, and obstacle for flood control. The performance of such infrastructures under ambient vibrations as well as the operational loads may reduce over their life-time. Failure of the dams leads to irreparable losses for beneficiary communities near these structures $[1,2]$. The most important catastrophes that occurred in the recent years include the failure in 1864 of a $30 \mathrm{~m}$ embankment dam which claimed 254 people in Sheffield, UK [3], Canyon lake dam that claimed the lives of 236 people in Texas, USA [4], and Austin dam disaster that claimed the lives of 78 people [5]. Hence, a continuous Structural Health Monitoring (SHM) framework is needed to prevent such sudden failures in the dams.

The process of identifying and tracking the structural damage in a civil, mechanical, or electrical infrastructure is known as structural health monitoring [6]. The existence of damage in a structural system changes its dynamic properties such as damping, natural frequencies, and mode shapes. Therefore, the damage state of a structure can be determined by identifying and evaluating these dynamic parameters [7]. In the following section, a comprehensive literature review of damage detection in structural systems as well as recent advances in SHM of dams is presented. 
1.1. Structural Damage Detection. Damage detection methods could be divided into two general categories, model-based and data-driven methods. In the former approach, a system identification algorithm should be employed for identifying the dynamic properties of the structure. Then, the structural health condition will be determined by capturing the variation of these dynamic properties. On the other hand, data-driven methods apply features extracted from the vibration response of the structure through a statistical learning algorithm to predict the damage [8]. Cui et al. [9] proposed a damage diagnosis procedure based on the natural excitation technique to identify the structural damage under ambient conditions. The authors combined the strain response with the Eigensystem realization algorithm to identify the strain modal parameters of a structure under ambient vibration. Montazer and Seyedpoor [10] presented a damage index based on flexibility index to detect the location of damage in truss systems. They implemented their proposed method on two numerical models, including a planar truss having 31 elements and a 47-bar planar power line tower. Lee and Eun [11] provided a static damage detection procedure by comparing the variation of stress distribution before and after damage. They showed the validity of their method utilizing two truss structures. Ding et al. [12] developed a method based on Modal Strain Energy (MSE) to identify the damage in the grid structures. They employed an updated mode shape expansion method to ensure that the modal shape obtained from the reference baseline model is reliable. Liu et al. [13] proposed a method based on Stationary Wavelet Transform (SWT) for the purpose of localization and severity detection of cracks in the cantilever beams. Montejo [14] evaluated different vibration-based damage diagnosis methods for the purpose of detecting the damage in the structures under ambient excitation. They concluded that the method based on Continuous Wavelet Transform (CWT) is much more efficient than uncovering the highfrequency spikes of the structural response obtained by Hilbert-Huang transform, high-pass filtering, or Discrete Wavelet Transform (DWT). Pu et al. [15] presented the use of Frequency Response Functions (FRFs) along with the model updating theory for identifying the damage occurred in concrete beams. They formulated an optimization algorithm to set the analytical FRFs from a benchmark finite element model with those obtained through the experimental response. Worden et al. [16] implemented a statistical approach based on Mahalanobis squared distances for healthy and damaged structures. This method was actually a novelty detection problem where a damaged structure should be diagnosed from the healthy cases. Ditommaso et al. [17] presented a method for damage detection of the framed-structures subjected to earthquake motions by evaluating the variation of modal curvature in the natural frequencies. They validated their method by using numerical models and implementing some experiments. Zhang et al. [18] proposed an innovative damage index according to the macrostrain modal shapes for the purpose of detecting the potential damage in steel bridges. Yazdanpanah et al. [19] presented a damage indicator based on modal information for damage detection in beam-like structures. Their method was founded on three factors, namely, the mode shape, the slope of the mode shape, and the curvature of the mode shape. Figueiredo et al. [20] compared four different machine learning techniques by applying autoassociative neural network, factor analysis, Mahalanobis distance, and singular value decomposition to identify the structural damage. They have implemented their study on an experimental baseexcited three-story frame structure. Ghiasi et al. [21] proposed a least square support vector machine based on the thin-plate spline Littlewood-Paley wavelet kernel function to identify the structural damage. Ghannadi and Kourehli [22] explored the efficiency of the moth flame optimization algorithm to identify the location and severity of structural damage. They used the Eigenvalues obtained from the equation of motion along with Modal Assurance Criteria (MAC) flexibility as damage indices. Nguyen et al. [23] presented a novel framework based on the transmissibility function fed to ANNs to identify the structural damage in bridges. They verified their method using data measured from an existing bridge in Taiwan.

1.2. Structural Health Monitoring of Dams. Wang and He [24] presented a methodology based on the reduction of natural frequencies to identify the crack location in arch dams. They proposed a statistical neural network to detect the crack by measuring the reductions of natural frequencies. Turker et al. [25] explored a method based on model updating to identify the global damage that occurred in the arch dams. They have validated their method on an experimental model under ambient excitation. Pirboudaghi et al. [26] proposed a multistage method based on the extended finite element method (XFEM) and continuous wavelet transform (CWT) to detect the seismic cracks of concrete dams. Sevim et al. [27] implemented an ambient vibration test to identify the dynamic properties of a real concrete arch dam, including modal frequencies, damping, and mode shapes. Bianchi and Bremen [28] proposed various procedures to capture the long-term performance of Ferden and Roggiasca dams in Switzerland. In this regard, they captured variations of the dam behavior before the snowfall and after the break period. Mata [29] conducted a comparative study on two statistical models named multiple linear regression (MLR) and neural network (NN) for monitoring of Alto Rabagão dam performance in the environmental condition. Seyed-Kolbadi et al. [30] evaluated the stability of the Boostan earth dam by processing its longterm performance and interpreting the measured data.

All the previous research assumed that the modal parameters of the dam are known. In fact, they directly used the modal parameter obtained from Finite Element (FE) analysis to identify the structural damage. It seems that there is a research gap in identifying the damage that occurred in dams especially when the modal parameters are calculated through the system identification process. In the light of previous research, in this paper, a combined method based on wavelet and Hilbert-Huang transform is proposed to identify the structural dynamics of the dam. In this regard, 
four commonly occurred damage scenarios, including damage in the neck, damage in the toe, simultaneous damage in the neck and the toe, and damage in the lifting joints of the dam, are considered to verify the capability of the proposed method. An optimization technique based on minimizing the nondiagonal entries of the MAC matrix is implemented to optimize the location of sensors needed to install at the body of the dam. Next, by adding $10 \%$ noise to the structural response under the ambient excitation, the dynamic properties of the structure are obtained for predefined locations, and the cubic-spline technique is used to make the mode shapes differentiable. In the following, damage location is estimated through employing CWT on the difference between the curvature of the mode shapes of the intact and damaged structure.

\section{Models and Materials}

2.1. Model Description. In this study, a well-known reservoir dam named "Koyna" was numerically modeled in Ansys finite element software, and further investigations were implemented on the response obtained through the numerical analysis. The following sections introduce the structural behavior and modeling procedure of the understudy dam. Fluid-Structure Interaction (FSI) is an important issue in both linear and nonlinear analyses of hydraulic structures. There are three main solutions to resolve this problem, including added mass method, Eulerian method, and Lagrangian method. The added mass method is related to additional mass considered in the system because of the existence of an accelerating or decelerating body that must move some volume of surrounding fluid as it moves through it. The Lagrangian method is related to individual particles, which calculates the trajectory of each particle independently. The Eulerian method is based on the concentration of particles and computes the general convection of the particles [31]. The coupled fluid-structure equation of motion can be easily solved by applying some proper boundary conditions for the reservoir object. Readers are encouraged to study the paper presented by Park et al. [32] for more information about fluid-structure interaction modeling.

There are various types of foundation modeling procedures, such as rigid foundation and massless and massed foundation. The rigid foundation model disregards the interaction between the dam and its foundation. Actually, the stiffness and mass of the foundation are not considered in the global coupled equation of motion. Besides, the massless foundation model considers the flexibility of foundation in the FE model. In this problem, the foundation model must stretch to a large length so that its effects on stresses and strains of the dam approach to an enough small value [33]. Generally, in FE models, the meshing system includes solid elements to model the dam body and reservoir. In order to model the reservoir domain, pressure-based fluid elements were applied. The reservoir of the dam is modeled threefifths of the dam's height. The water is defined as a linearly compressible and small-amplitude material. The Helmholtz equation is implemented as governing equation in the reservoir medium, as shown in Figure 1. In addition, the boundary conditions considered for the modeling procedure are shown in this figure [34]. The coupled equation of the dam-foundation-reservoir system can be written as follows:

$$
\left[\begin{array}{cc}
M_{s} & 0 \\
\rho_{w} Q_{\mathrm{FSI}}^{T} & M_{F}
\end{array}\right]\{\ddot{U} \ddot{P}\}+\left[\begin{array}{cc}
C_{s} & 0 \\
0 & C_{F}
\end{array}\right]\left\{\begin{array}{c}
\dot{U} \\
\dot{P}
\end{array}\right\}+\left[\begin{array}{cc}
K_{s} & -Q_{\mathrm{FSI}} \\
0 & K_{F}
\end{array}\right]\left\{\begin{array}{l}
U \\
P
\end{array}\right\}=\left[\begin{array}{c}
F_{\text {str }} \\
F_{\mathrm{acc}}
\end{array}\right],
$$

where $K, C$, and $M$ are stiffness, damping, and mass matrices, $F_{\text {str }}$ is the summation of external forces and ground excitation on the solid domain, $Q_{\mathrm{FSI}}$ is fluid-structure coupling matrix, $F_{\text {acc }}$ is the summation of the forces that arise from ground motions on solid-fluid boundaries and the total acceleration acts on the other boundaries, $P$ and $U$ are the hydrodynamic pressures and displacements, and the subscripts " $F$ " and " $S$ " refer to fluid and structure, respectively.

2.2. Case Study. Koyna gravity dam is founded in India with a crest length equal to $807 \mathrm{~m}$ and a height of $103 \mathrm{~m}$. Its thickness at the base and the crest is 70.2 and $12.1 \mathrm{~m}$, respectively. The 1967 Koynanagar event imposed intensive damages to the dam, including horizontal cracks on the upstream and downstream faces, as a result of which the slope of the downstream face changes significantly [35]. Table 1 presents the mechanical properties of the concrete and the acoustic properties used to model the water dynamics.

According to the large dimensions in the cross-stream direction, the assumption of plane strain is applicable for gravity dams. Therefore, these structures are usually modeled and analyzed as 2D structures [36-38].

2.3. Modal Analysis. By discarding the damping term in the coupled equation of motion, one can derive the Eigenvalues of the undamped FE model as defined by Hariri-Ardebili and Saouma [33]. Since the mass matrix and stiffness matrix are unsymmetric, the Lanczos formulation is implemented to solve this equation. This technique uses a secondary variable and the undamped coupled equation is written as [39]

$$
\left(\left[\begin{array}{ccc}
K_{S} & -Q_{\mathrm{FSI}} & 0 \\
-Q_{\mathrm{FSI}}^{T} & -M_{F} & K_{F} \\
0 & K_{F}^{T} & 0
\end{array}\right]-\left[\begin{array}{ccc}
M_{S} & 0 & 0 \\
0 & 0 & 0 \\
0 & 0 & K_{F}
\end{array}\right]\right)\left\{\begin{array}{l}
U \\
P \\
\Theta
\end{array}\right\}=\left\{\begin{array}{l}
0 \\
0 \\
0
\end{array}\right\},
$$

where $\Theta$ is equal to $\left(1 / \omega^{2}\right) \mathbf{P}$. Readers are encouraged to study the paper presented by Hariri-Ardebili and Saouma [33] for more information about FSI and modal analysis of the dam.

\section{Methodology}

3.1. Proposed Framework. This study presents a cost-effective method for the purpose of identifying dynamic properties and damage location of the dams. The optimum locations for sensor placements were determined through minimizing the nondiagonal entries of the MAC matrix. In 


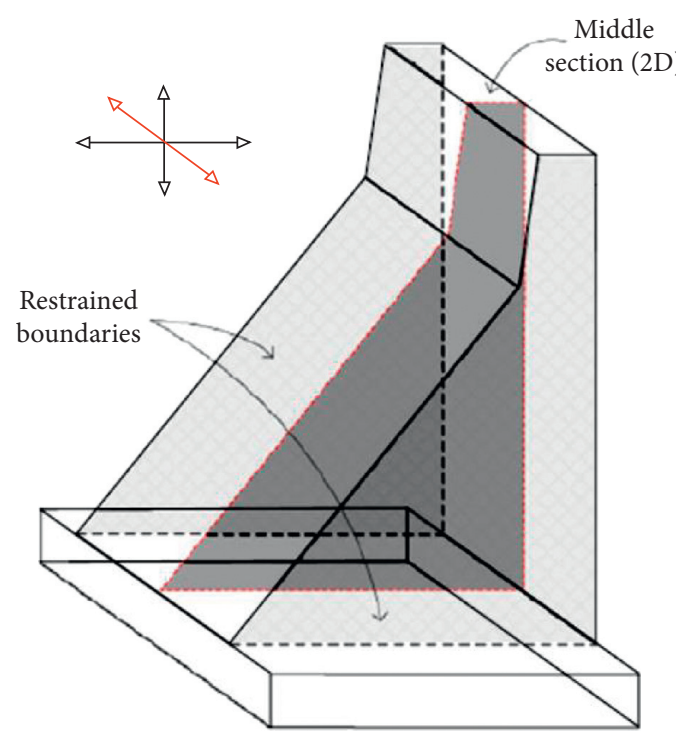

(a)

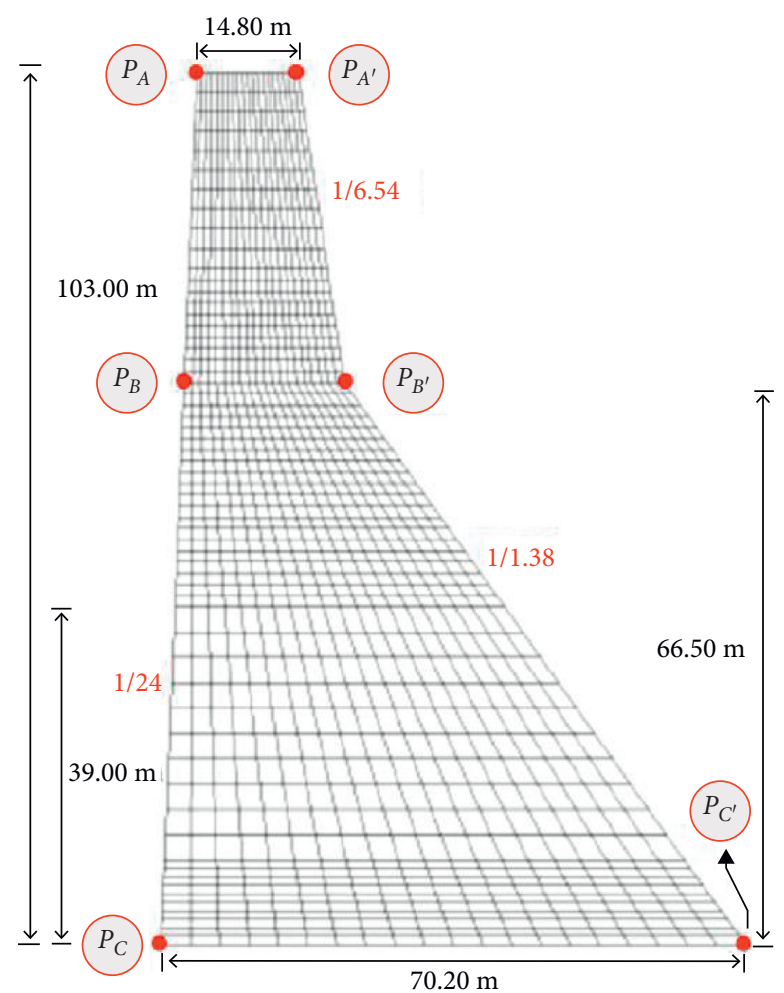

(b)

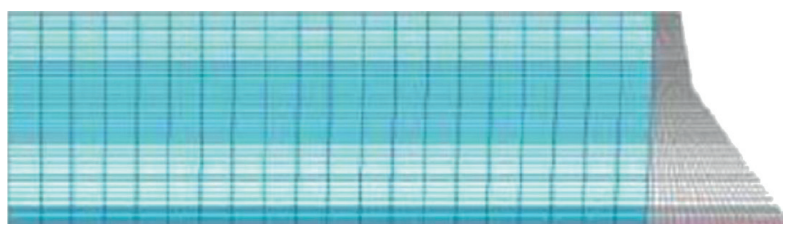

(c)

FIgURE 1: Numerical model of Koyna dam. (a) Schematic view of 3D model. (b) Mesh distribution at considered middle section. (c) Overall view of coupled dam-reservoir foundation system.

TABLE 1: Mechanical properties of the dam body and reservoir water.

\begin{tabular}{lcccc}
\hline Model part & Characteristic & Unit & Static & Dynamic \\
& Modulus of elasticity & $\mathrm{GPa}$ & 31.0 & 35.7 \\
Dam body & Poisson's ratio & - & 0.02 & 0.14 \\
& Density & $\mathrm{Kg} / \mathrm{m}^{3}$ & 2643 & 2643 \\
\multirow{2}{*}{ Reservoir water } & Sonic velocity & $\mathrm{m} / \mathrm{s}$ & - & - \\
& Density & $\mathrm{Kg} / \mathrm{m}^{3}$ & 1000 & 1000 \\
\hline
\end{tabular}

consequence, the dynamic properties of the dam were determined by processing the output signals captured from the structure under ambient vibration excitation. The dynamic properties of a structure will change by causing a damage to the body of the dam. The proposed method is based on the difference between curvature of the mode shapes in the healthy and defective structures. Eventually, by applying the continuous wavelet transform (CWT) on the residual of the curvature of the mode shapes, the location of the damage is estimated. Figure 2 shows the general view of the proposed framework.

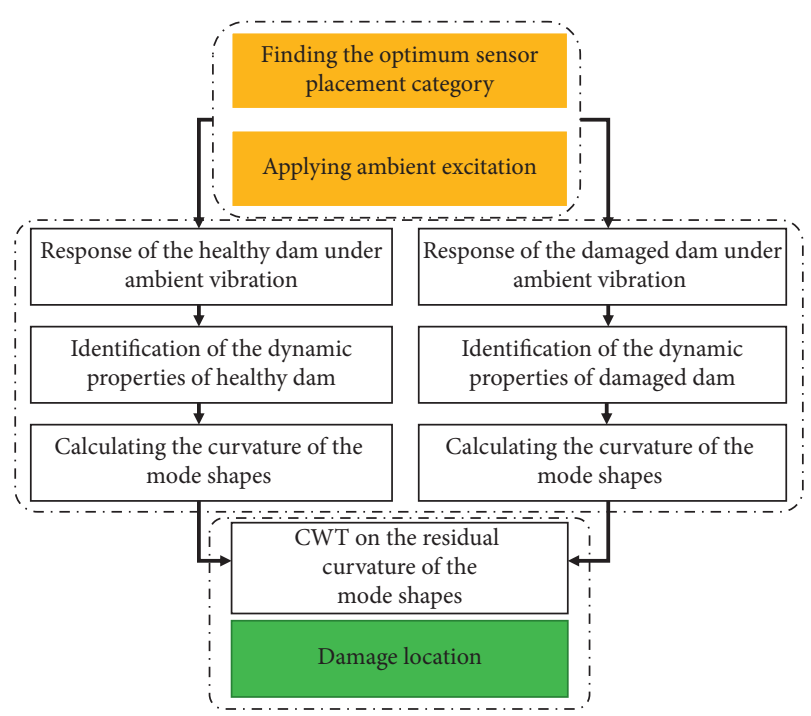

FIGURE 2: Main algorithm of the proposed method. 
3.2. Theoretical Background of Continuous Wavelet Transform. Since the foundation of the proposed method is based on continuous wavelet transform, it is essential to present a brief theoretical background for the readers who are less familiar with the topic. A wavelet is a function $\psi(t) \in L^{2}(\Re)$ with zero mean and defined as follows $[40,41]$ :

$$
\psi_{a, b}(t)=|a|^{-0.5} \psi\left(\frac{t-b}{a}\right), \quad a>0,
$$

where $L^{2}(\Re)$ is the set of integrable functions, $a$ and $b$ are scale and translation parameters, respectively, and $|a|^{-0.5}$ is used to ensure that $\left\|\psi_{a, b}\right\|$ is equal to unity. Also, $\psi$ is the wavelet function (the mother wavelet), which must satisfy the admissibility condition

$$
C_{\psi}=\int_{-\infty}^{+\infty} \frac{|\widehat{\psi}(\omega)|^{2}}{|\omega|} \mathrm{d} \omega<\infty,
$$

where $\omega$ is the frequency, and $\widehat{\psi}(\omega)$ is the Fourier transform of $\psi$. The continuous wavelet transform of $x(t)$ is the inner product of the family of wavelets $\psi_{a, b}(t)$ with the signal $x(t)$ as follows:

$$
F_{W}(a, b)=\left\langle x(t), \psi_{a, b}(t)\right\rangle=\int_{-\infty}^{+\infty} \frac{x(t)}{\sqrt{a}} \psi^{*}\left(\frac{t-b}{a}\right) \mathrm{d} t,
$$

where $\psi^{*}$ is the complex conjugate of $\psi$. This condition guarantees the workability of the signal to be used as the mother wavelet in continuous wavelet transform. In this study, two different mother wavelets were used, i.e., Morlet and Daubechies. Complex Morlet wavelet has a close form to the following equation and applied to identify the modal properties of the dam:

$$
\psi(t)=\frac{1}{\sqrt{\pi}} e^{-t^{2}} e^{i \omega_{0} t},
$$

where $t$ is the time, and $\omega_{0}$ is the central frequency of the wavelet. By applying $a$ as dilation and $b$ as translation, a son wavelet is written as follows:

$$
\psi_{a, b}(t)=\frac{1}{\sqrt{a \pi}} e^{-(t-b / a)^{2}} e^{i \omega_{0}(t-b / a)},
$$

On the other hand, Daubechies wavelets are defined by computing the running average and difference of scalar products with wavelets and scaling signals. As the Daubechies wavelets apply overlapped windows, the high-frequency coefficient spectrum presents all high-frequency variations. It can be used as an appropriate wavelet to identify the high-frequency jumps resulting from damage in the response signal of the structures [42]. Therefore, the Daubechies mother wavelet was implemented to identify the structural damage that occurred in the dam.

3.3. Mathematics of Cubic Spline. The cubic-spline interpolation was presented to the best curve fitting between some discrete values. The cubic spline includes a set of weights connected to a plane surface where the points are connected. A flexible strip is curved through each of these weights, which forms a straight and smooth curve. The foundation of this interpolation method is based on curve fitting of piecewise-defined function with the below form:

$$
h(x)= \begin{cases}h_{1}(x), & \text { if } x_{1} \leq x<x_{2}, \\ h_{2}(x), & \text { if } x_{2} \leq x<x_{3}, \\ \ldots & \\ h_{n}(x), & \text { if } x_{n-1} \leq x<x_{n},\end{cases}
$$

where $h_{i}$ is a third polynomial function. The cubic spline must have the below conditions:

(1) The piecewise-defined function should interpolate all the points.

(2) $h(x), h^{\prime}(x)$, and $h^{\prime \prime}(x)$ should be continuous in $\left[x_{1}, x_{n}\right]$; the cubic spline is widely applied to determine the slope (or cumulative variation) of a finite number of variables over an interval [43].

\section{System Identification}

4.1. Input Excitation. The input excitation considered to simulate the ambient vibration excitation to the dam was a Gaussian white noise signal. White noise is a random signal enjoying the same intensity at different frequencies, which provides a constant power spectral density. The rand $n$ function of MATLAB [44] was utilized to generate a white noise signal. The total time of the input signal was $1200 \mathrm{~s}$, with the time step of $0.01 \mathrm{~s}$. It should be noted that the input signal was applied to the whole structure of the dam for simulating the real condition. The dynamic characterization of the dam was performed by implementing ambient vibration analysis. It should be noted that the key reason for using such a long-duration signal was to reach a stationary condition, which was essential for proper ambient vibration analysis. Figure 3 illustrates the input excitation subjected to the dam.

4.2. Sensor Location Optimization. One of the main objectives of the present study was to optimize the location of sensors. Therefore, it was necessary to know how to place these instruments in such a way that the maximum agreement between the numerical modal shapes and those obtained through the finite number of sensors be obtained. In order to achieve an economical plan, as well as effective coverage of the whole dam body in terms of detecting the probable damage, the team decided to place only six sensors in this study. The following steps were implemented to determine the optimal locations:

(i) First, the height of the dam was divided into 60 locations, where it is possible to place the sensors.

(ii) Second, the mode shapes of the dam were determined for all the possible nodes by applying modal analysis. Figure 4 illustrates the first three mode shapes of the dam for 60 possible nodes. 


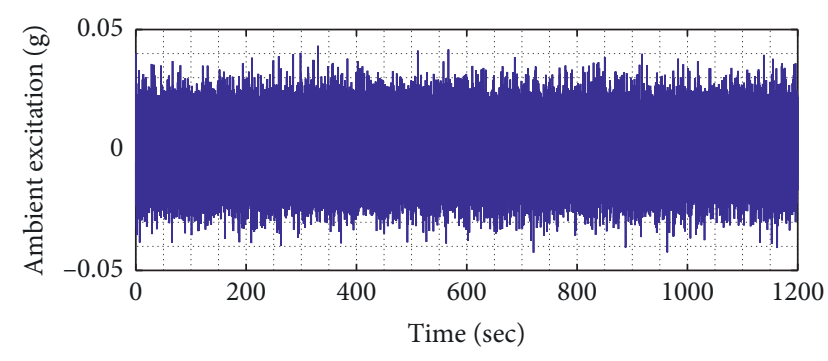

Figure 3: Input excitation signal.

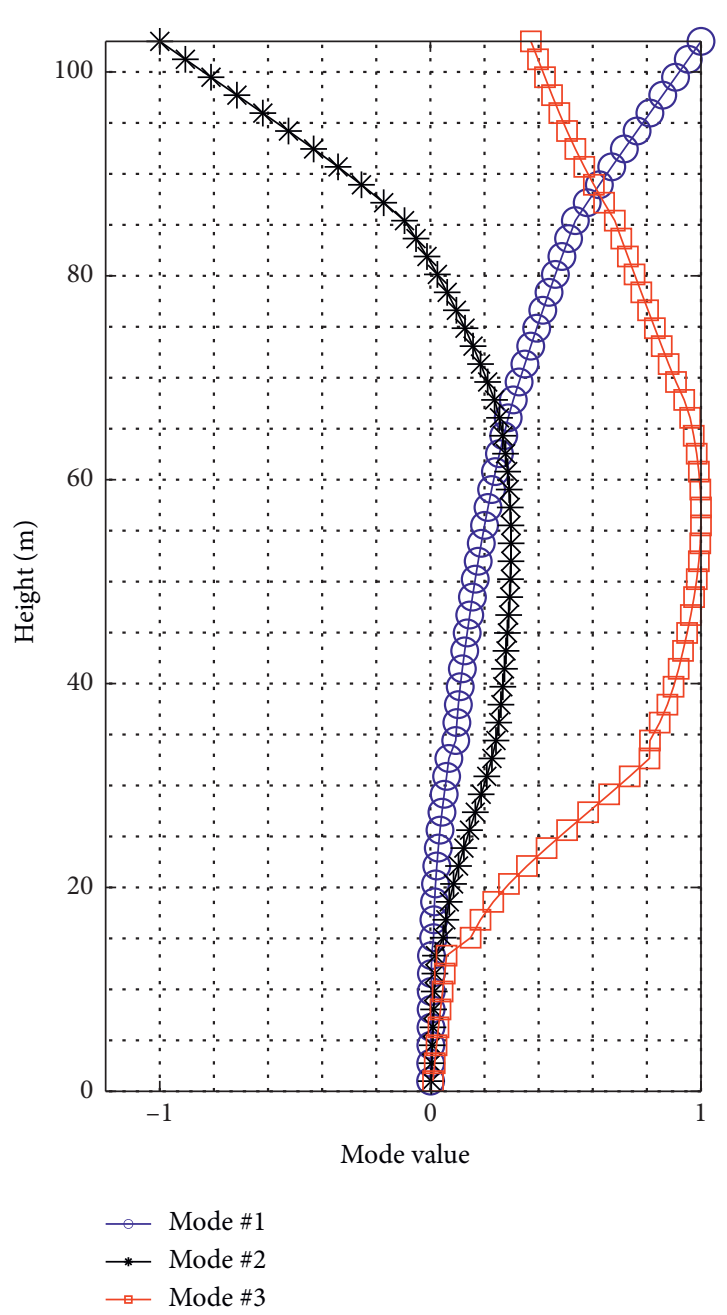

Figure 4: Mode shapes of the dam according to 60 possible nodes for sensor placement.

(iii) Third, six intended sensors should be placed at the possible nodes to achieve the maximum linear independency. In fact, the instrumentation should be conducted so that the nondiagonal entries of the MAC matrix converge to their minimum values [45]. To do so, the first sensor was placed at the summit of the dam. The next sensor was placed at one of the 59 remaining locations so that the nondiagonal entries of the MAC matrix became minimum. (iv) This operation was repeated for other remained sensors until the best agreement was reached. Finally, the optimal location of the sensors was determined, as shown in Figure 5.

4.3. Free Vibration. In order to extract information about the dynamic properties of a structure from acceleration sensors, the vibration response of those structures must be measured. To this end, in this study, the random decrement technique (RDT) [46] was used. The concept behind the $\mathrm{RDT}$ is that by extracting a large number of time segments from the generated signal and averaging such signals, the random part of the response will continue to disappear from the system and only the response to the initial conditions will remain. For example, Figures $6(\mathrm{a})$ and $6(\mathrm{~b})$ show the response of sensor no. 5 under ambient vibration excitation and corresponding free vibration obtained through RDT.

4.4. Mode Decomposition. The Continuous Wavelet Transform (CWT) of the free-vibration response gives time and scales coefficients of the wavelet coefficient contours. Considering this, a complex Morlet wavelet with a central frequency of 4.57 was used. As an example, Figure 7 depicts an instance of wavelet coefficients obtained for sensors no. 1 and no. 6 . In the next step, the free vibration associated with each vibrating mode can be achieved by a plotting summation of the wavelet coefficient at a point where the wavelet coefficients were maximum (maximum of contours). In other words, one should find the local maximum of the wavelet contours presented in Figure 7 . Then, by applying the complex Morlet wavelet to the signal obtained from these peak values and plotting the imaginary parts of the wavelet coefficient, free vibration of each mode will be obtained according to each peak value.

4.5. Modal Damping and Natural Frequencies. The Hilbert transform of the free vibration was then calculated to determine the natural frequency and modal damping ratio of each mode. Figure 8 displays an algorithm for computing the dynamic properties. The steps in this algorithm are as follows:

(1) Hilbert transform was applied to the free vibration of each mode

(2) The phase and amplitude of the signal obtained in the previous step was computed

(3) The rate of change of the amplitude and the phase signal are considered as $-\zeta_{i} \omega_{i}$ and $\omega_{D i}$, respectively

(4) Finally, the fundamental concepts from dynamics of structures were used to find $\omega_{i}$ and $\zeta_{i}$

For example, in an attempt to calculate the first and second natural frequencies, as well as modal damping ratios, it is required to employ the scaling of 60 in wavelet coefficient for the first mode and the scale of 145 in wavelet coefficient for the second mode as shown in Figure 7. According to Figure 8, the slope of $L_{21}$ in the linear region is 


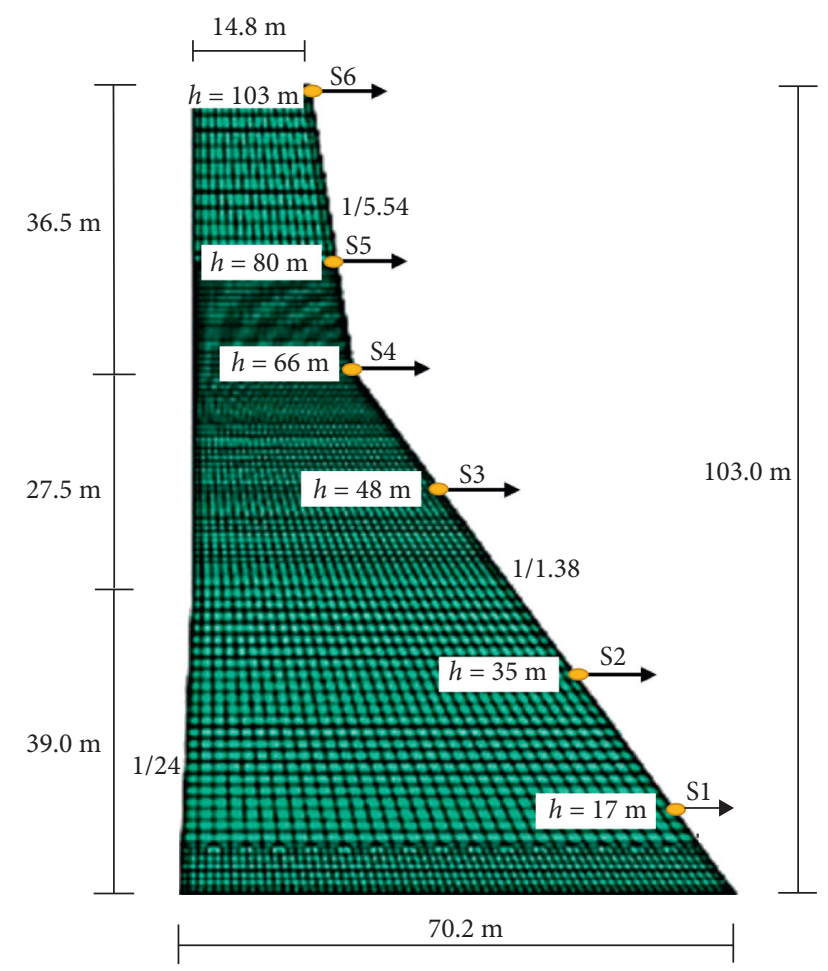

Figure 5: Optimal sensor location.

$\omega_{D 1}$, which is equal to $\omega_{D 1}=24.4 \mathrm{rad}$ (see Figure 9(a)). In addition, the slope of $L_{11}$ in the linear region is $-\zeta_{1} \omega_{1}$, and as shown in Figure 9(b), the natural frequency and damping ratio of the first vibrating mode are obtained by implementing the following simple calculations:

$$
\begin{aligned}
& \omega_{D 1}=244.0 / 10=24.4 \mathrm{~Hz} \\
& -\zeta_{1} \omega_{1}=-1.05 \longrightarrow \omega_{1}= \\
& 24.4 / \sqrt{1-\left(1.05 / \omega_{1}\right)^{2}} \longrightarrow \omega_{1}=24.42 \mathrm{rad} \longrightarrow \\
& f_{1}=3.88 \mathrm{~Hz} \text { and } \zeta_{1}=1.05 / 24.42=0.043
\end{aligned}
$$

and

It is worth noting that using the same procedure, the second mode properties can be calculated. As illustrated in Figure 8, the slope of $L_{22}$ in the linear region is $\omega_{D 2}$, which is obtained as $\omega_{D 2}=45.9 \mathrm{rad}$ (see Figure 9(c)). Furthermore, the slope of $L_{12}$ in the linear region is $-\zeta_{2} \omega_{2}$, and according to Figure 9(d), the natural frequency and damping ratio of the second mode can be computed by the following calculations:

$$
\begin{aligned}
& \omega_{D 2}=459.0 / 10=45.9 \mathrm{~Hz} \\
& -\zeta_{2} \omega_{2}=-1.125 \longrightarrow \omega_{2}= \\
& 45.9 / \sqrt{1-\left(1.125 / \omega_{1}\right)^{2}} \longrightarrow \omega_{2}=45.92 \mathrm{rad} \longrightarrow \\
& f_{2}=7.31 \mathrm{~Hz} \text { and } \zeta_{2}=1.125 / 45.92=0.025
\end{aligned}
$$

and

The first three natural frequencies and modal damping of the dam are calculated as shown in Table 2.

4.6. Noise Effect. In general, noise is an inevitable part of any measurement. Hence, there is a concept known as the Signal-to-Noise Ratio (SNR), which is defined as the ratio of signal power to the noise power, and commonly stated in decibels $(\mathrm{dB})$. A ratio higher than 1 denotes a higher amount of signal than noise [41]:

$$
\mathrm{SNR}=\frac{\sigma_{\text {signal }}^{2}}{\sigma_{\text {noise }}^{2}}
$$

where $\sigma_{\text {signal }}^{2}$ is the variance of signal and $\sigma_{\text {noise }}^{2}$ represents the variance of the noise. For a more realistic simulation, an appropriate level of noise needs to be applied to the acceleration time history. In the present study, the structural response is polluted by $10 \%$ noise to evaluate the practical application of the proposed method. It is proved that this value is the upper bound value of noise used in the previous studies [47]. Table 2 also presents the effect of noise on the obtained modal parameter of the dam. The results show that the proposed method had a promising ability to identify the modal parameters of the dam in the presence of noise.

4.7. Mode Shape Identification. In an attempt to identify the structural mode shapes, a method presented by Yang et al. [43] is utilized. From the previous sections, it can be concluded that while the damping ratio and natural frequencies can be estimated by only one sensor, the acceleration time histories at all DOFs are required and should be measured to identify mode shapes. The absolute values of Eigenvectors (mode shapes) can be obtained using the below relation:

$$
\frac{\left|\varphi_{p i}\right|}{\left|\varphi_{q i}\right|}=\exp \left[A_{p i}^{\prime}\left(t_{0}\right)-A_{q i}^{\prime}\left(t_{0}\right)\right],
$$

where $\varphi_{p i}$ is the $i_{\text {th }}$ mode shape at the $p_{\text {th }}$ degree of freedom. Similar definition is valid for $\varphi_{q i}$. The parameters $A_{p i}^{\prime}\left(t_{0}\right)$ and $A_{q i}^{\prime}\left(t_{0}\right)$ are the values calculated from curve fitting of $L_{2 i}$ for $p_{\text {th }}$ and $q_{\text {th }}$ degrees of freedom at time $t_{0}$, respectively. It is notable that $t_{0}$ is the time at the median value of $L_{2 i}$. McKinley and Levine [48] presented the below equation to calculate the sign of the mode shape at each degree of freedom:

$$
\varphi_{p i, q}=\theta_{p i}^{\prime}\left(t_{0}\right)-\theta_{q i}^{\prime}\left(t_{0}\right)
$$

where $\varphi_{p i, q}$ denotes the difference between the phase value of two signals in $p_{\text {th }}$ and $q_{\text {th }}$ DOF and $i_{\text {th }}$ mode. In addition, $\theta_{p i}^{\prime}\left(t_{0}\right)$ and $\theta_{q i}^{\prime}\left(t_{0}\right)$ are the values obtained through curve fitting to $L_{1 i}$ for $p_{\text {th }}$ and $q_{\text {th }}$ degree of freedom at time $t_{0}$, respectively. As the previous equation defines only the absolute value of mode shapes, in order to determine the sign of the mode shape entries, the following relations are presented:

$$
\text { if } \begin{aligned}
\varphi_{p i, q} & =\mp 2 m \pi \longrightarrow \frac{\varphi_{p i}}{\varphi_{q i}}>0 \text { and if } \varphi_{p i, q} \\
& =\mp(2 m+1) \pi \longrightarrow \frac{\varphi_{p i}}{\varphi_{q i}}<0 .
\end{aligned}
$$

By applying the abovementioned relations, the mode shape entries can be determined on the basis of free-vibration response of each mode with significant modal 


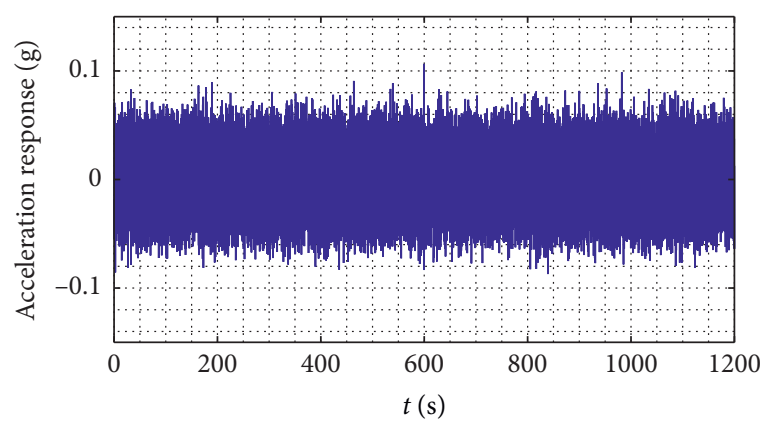

(a)

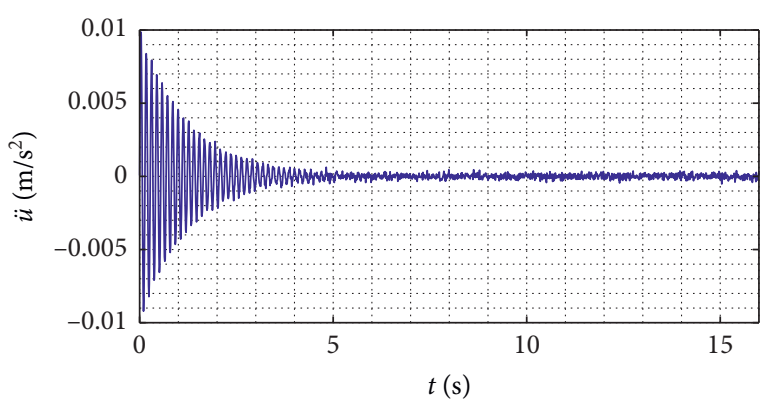

(b)

FIgURE 6: (a) Response recorded by sensor no. 5. (b) Free vibration obtained by RDT.

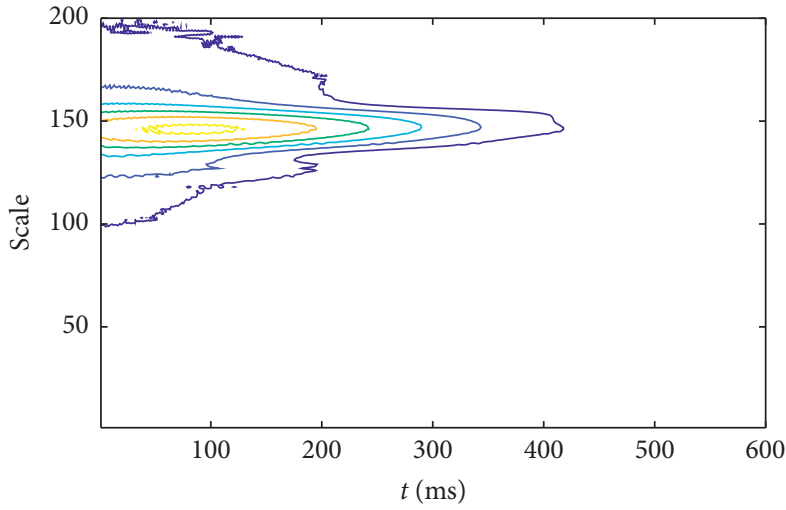

(a)

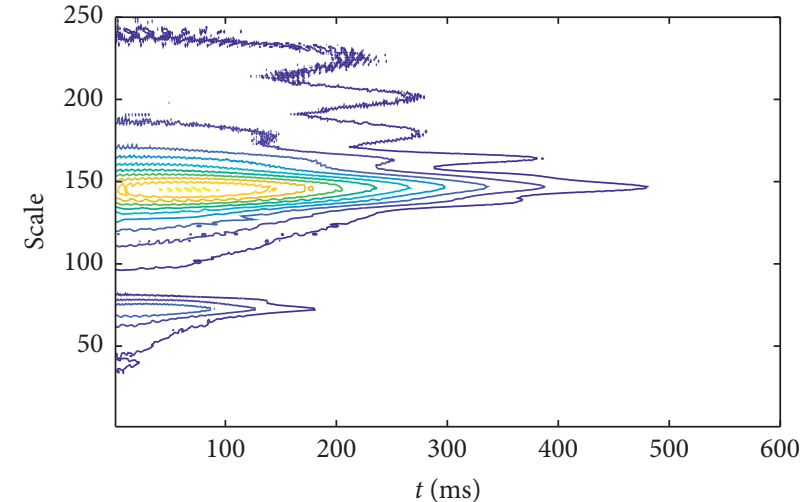

(b)

Figure 7: Wavelet coefficient contours. (a) Sensor no. 1; scale: 1,200. (b) Sensor no. 5; scale: 1,250.

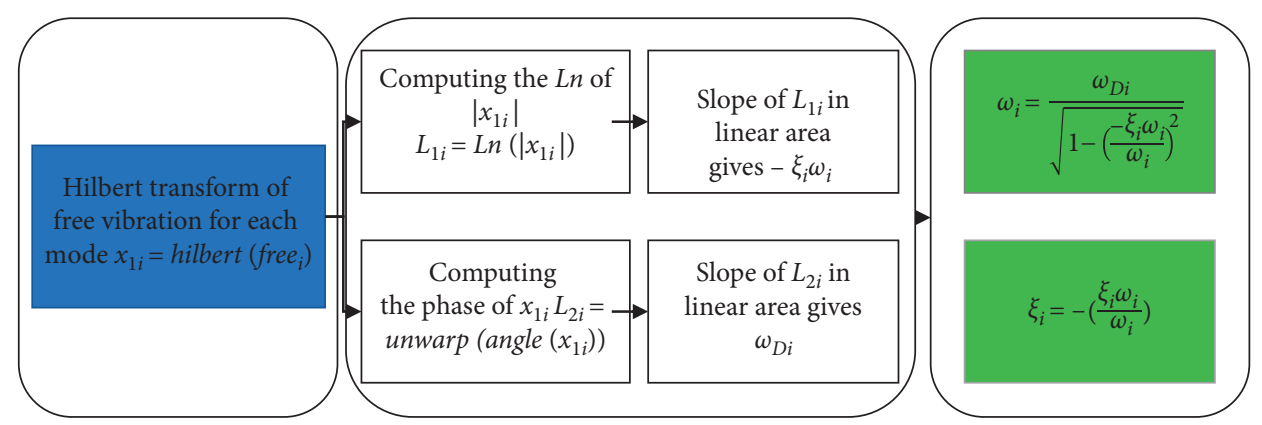

FIgURE 8: Algorithm for computing $\zeta_{i}$ and $\omega_{i}$.

participating mass ratio. Comparison between finite element analysis mode shapes and corresponding signal processing (SP) values is shown in Figure 10. The results indicate that the mode shapes are identified with a similar trend. However, it is clear that the third mode shape was estimated with more errors as compared to the first two modes. In fact, variations in the mode values due to damage were less than the errors observed in identification process. This indeed makes this mode shape useless for identifying the structural damage.

In order to evaluate the efficiency of the cubic-spline technique, mode shapes obtained through the system identification (SI) process are compared with those modified by cubic spline (CS). Figure 11 illustrates the effectiveness of cubic spline in smoothing and interpolating the mode shapes.

\section{Damage Detection}

5.1. Proposed Method for Damage Detection. The presented method is based on applying CWT on the residual curvature of the mode shapes. Therefore, the curvature of the mode shapes was determined by using the following relation [49]:

$$
\phi_{i}^{\prime \prime}=\frac{\phi_{i+1}-2 \phi_{i}+\phi_{i-1}}{d h},
$$




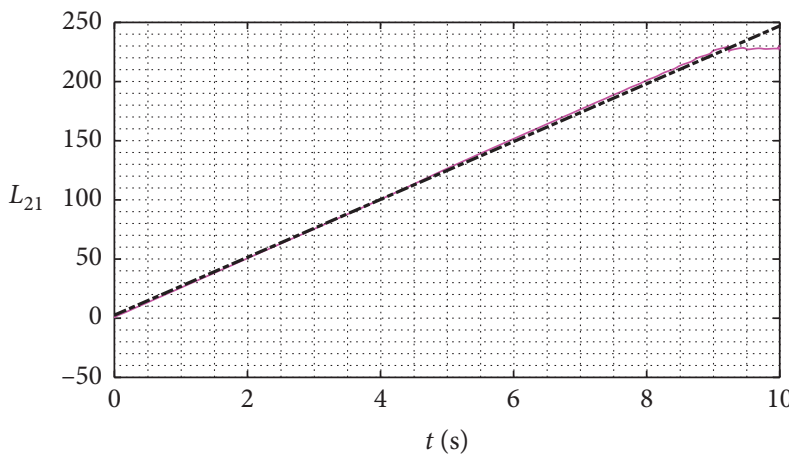

(a)

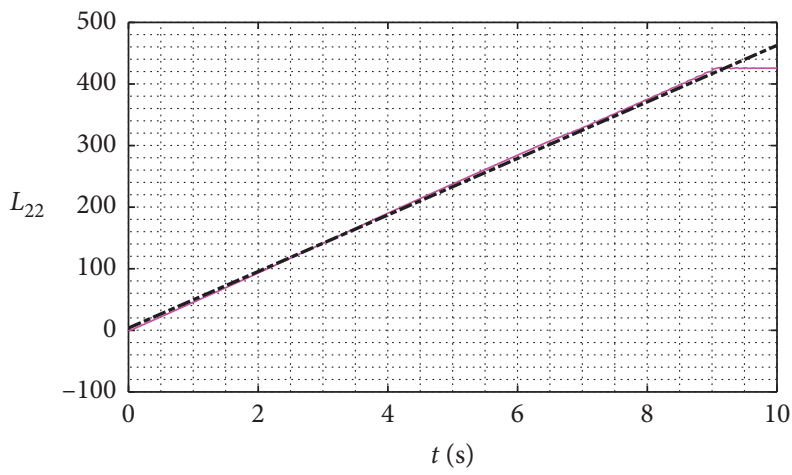

(c)

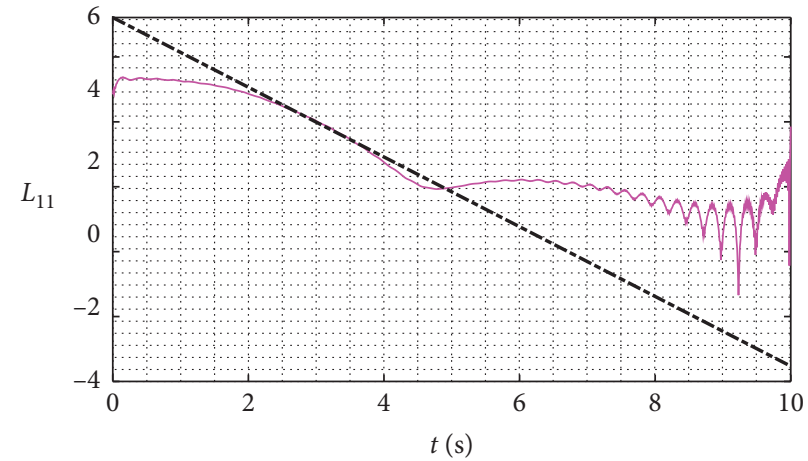

(b)

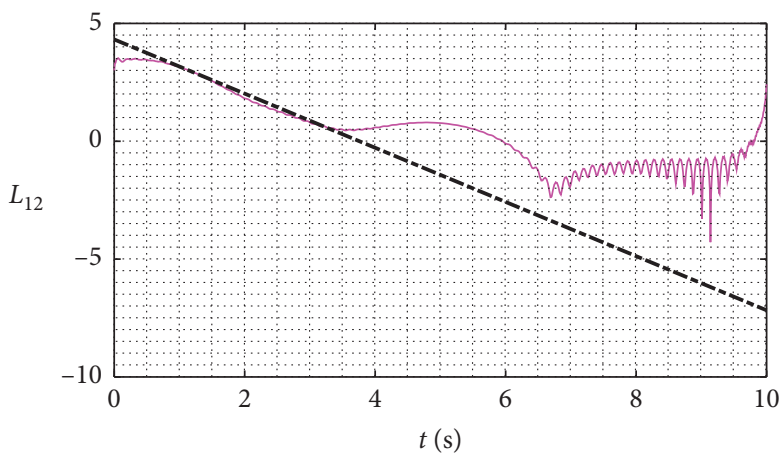

(d)

FIgURE 9: Curve fitting to extract the dynamic properties. First row for the first mode $(i=1)$ and second row for the second mode $(i=2)$.

TABLE 2: Estimated modal parameters.

\begin{tabular}{ccccccc}
\hline \multirow{2}{*}{ Mode } & \multicolumn{2}{c}{ Finite element model } & \multicolumn{2}{c}{ Without noise } & \multicolumn{2}{c}{ With 10\% noise } \\
& Frequency (Hz) & Damping ratio (\%) & Frequency (Hz) & Damping ratio (\%) & Frequency (Hz) & Damping ratio (\%) \\
\hline 1 & 3.67 & 4.0 & 3.88 & 4.3 & 3.92 & 4.2 \\
2 & 7.95 & 4.0 & 7.31 & 2.5 & 7.45 & 3.1 \\
3 & 11.80 & 4.0 & 11.91 & 4.1 & 11.82 & 4.2 \\
\hline
\end{tabular}

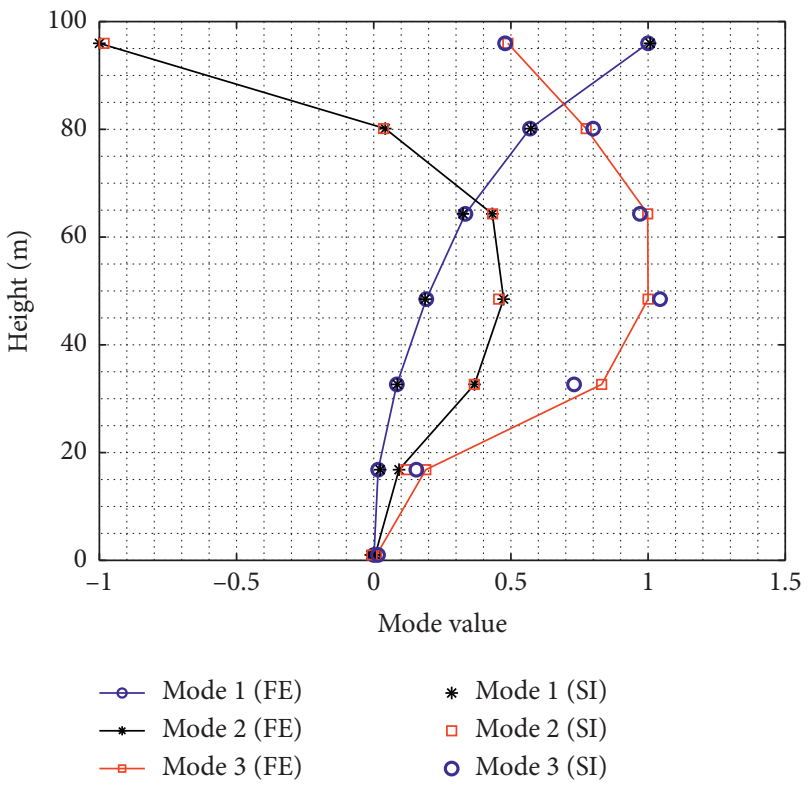

Figure 10: Difference between the mode shapes obtained by Finite Element (FE) analysis and System Identification (SI).

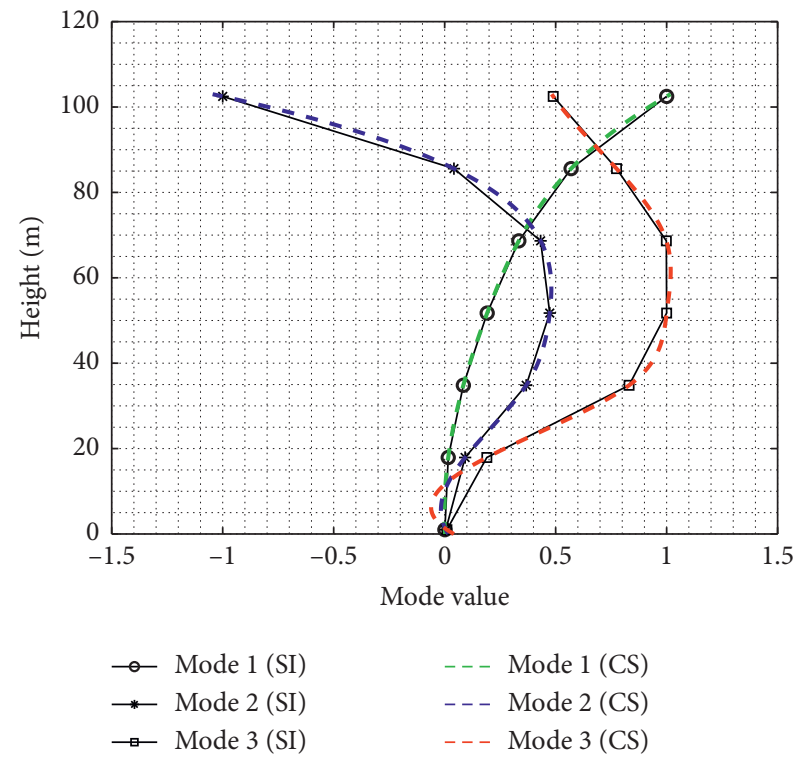

FIgURE 11: Comparison between identified model shapes and interpolated ones. 


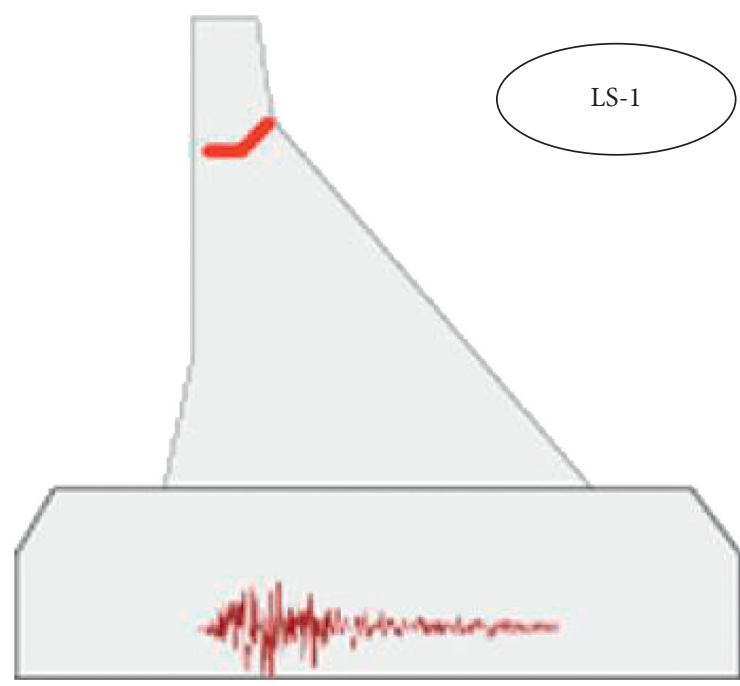

(a)

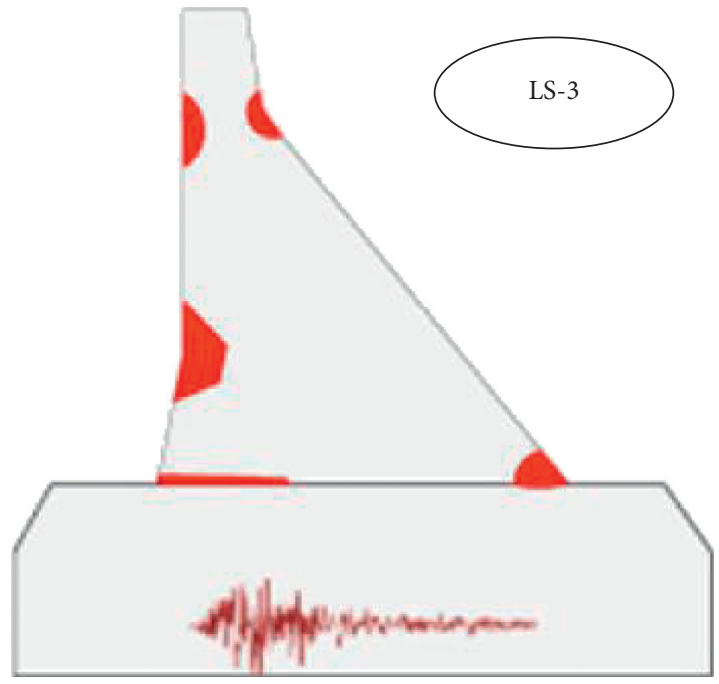

(c)

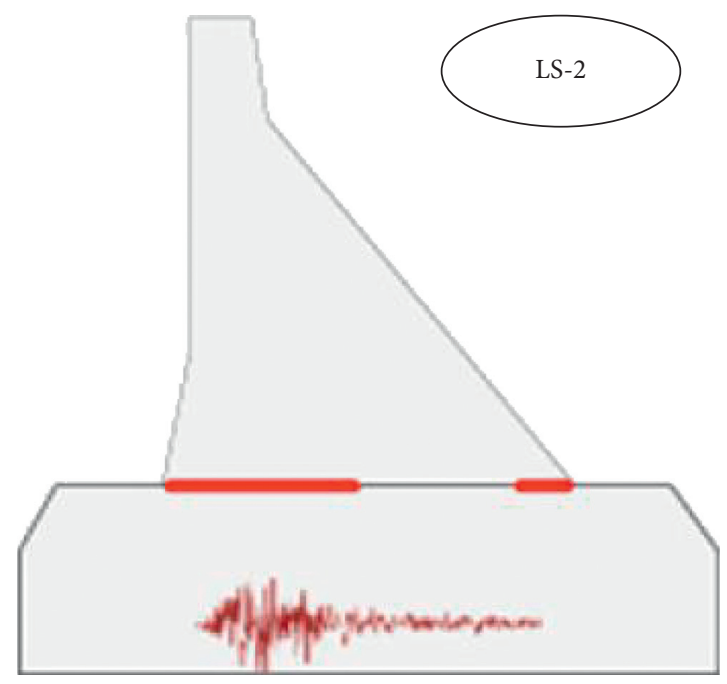

(b)

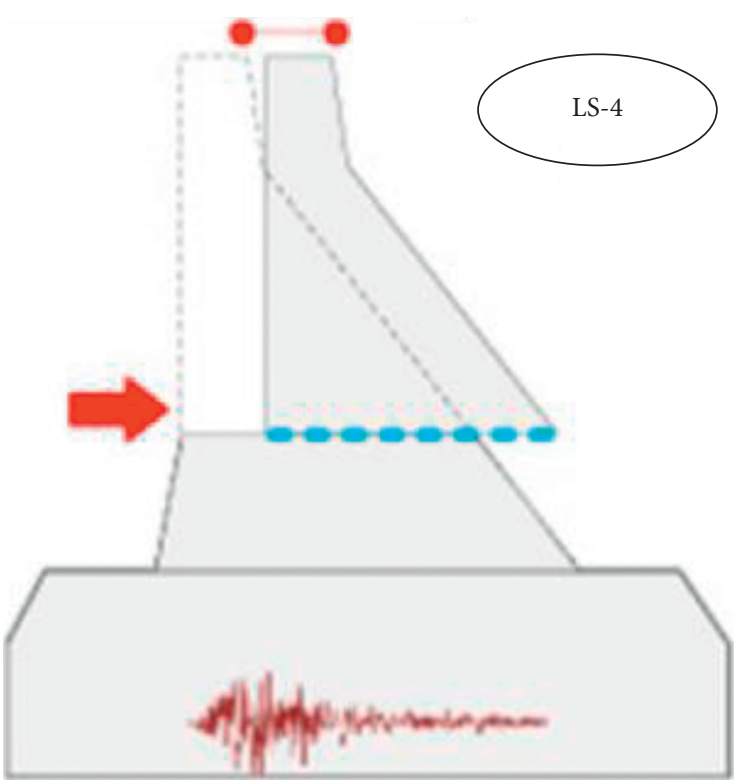

(d)

Figure 12: Damage scenarios. (a) Damage in the neck. (b) Damage in the toe. (c) Simultaneous damage. (d) Damage in lift joint elements.

where $\phi_{i}$ is the mode shape value at the $i^{\text {th }}$ height increment and $d h$ is the corresponding height step. In general, a large enough number of data are needed to calculate the slope and the curvature of the mode shapes. Nevertheless, the present study aims to identify the structural properties as well as the damage by implementing only six sensors. This leads to only six data points for each mode shape, which makes it impossible to calculate the curvature of the signal. To address this issue, cubic spline technique was implemented in MATLAB [33] to create enough data for computing the rate of change as well as the curvature of the mode shapes. Next, the difference between the curvature of the interpolated mode shape in the healthy and damaged structures was obtained. Eventually, by applying CWTon the residual vector of the mode shape's curvature, the location of damage was determined. As mentioned before, Daubechies wavelets were used to capture the changes occurring in the mode shape's curvature because of the structural damage.

5.2. Damage Scenarios. The general potential failure mechanisms in concrete gravity dams are overstressing, sliding along the weak surface. The intense earthquake may create tensile cracks at the base or near the downstream slope change discontinuity in concrete gravity dams. In certain earthquake motions, depending on whether the earthquake is near-field or far-field, simultaneous tensile cracks are observed in the neck and toe of the dam. In addition, rigid sliding at the lifting joints of dam was reported as a potential damage scenario for near-field motions [33]. To validate the presented method, four damage scenarios were considered as follows: 


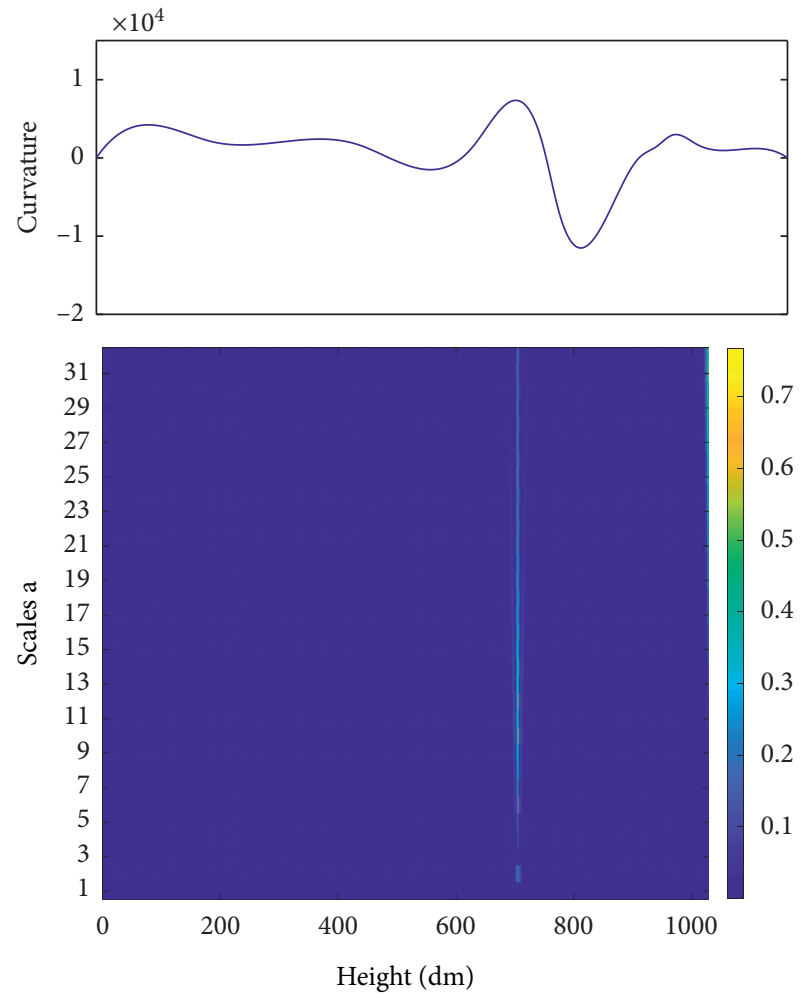

(a)

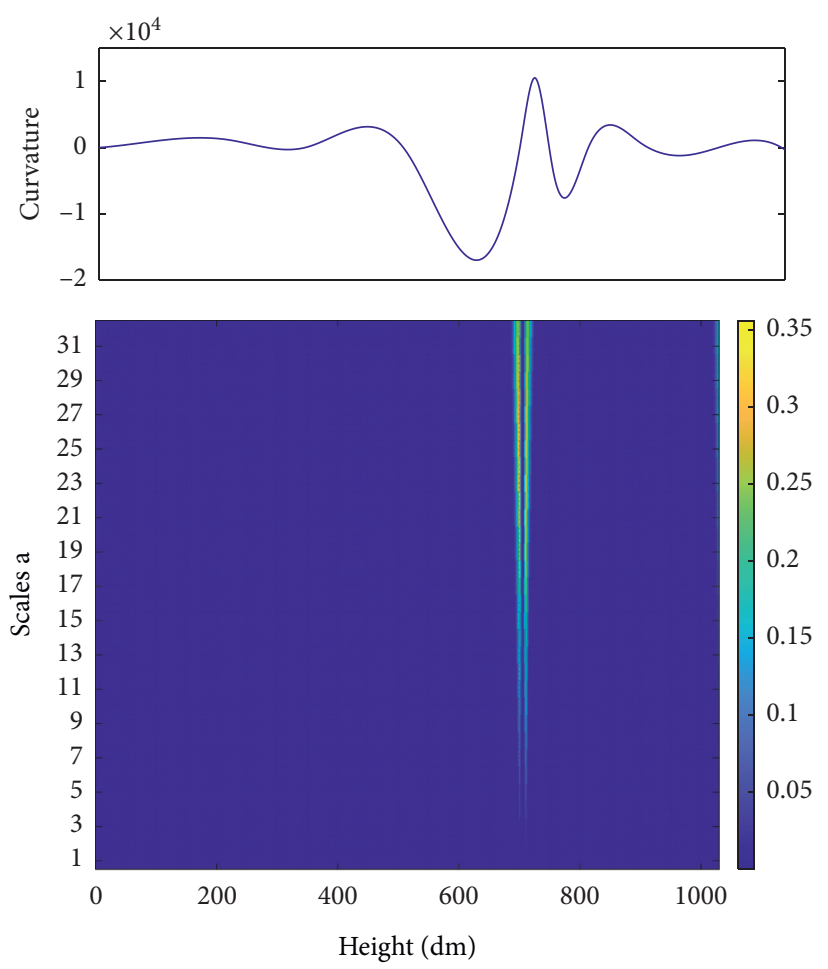

(b)

FIGURE 13: Residual value of mode-shape curvature and corresponding scalogram of CWT for the first scenario (damage in the neck). (a) First mode. (b) Second mode.

(i) Scenario 1. Neck: stiffness of a small region in the neck of the dam is reduced to $10 \%$ of its value in the healthy condition, as shown in Figure 12(a). To understand the extent of damage, the ratio of the defective elements to the total number of elements of the dam can be used. For example, in this scenario, $0.25 \%$ of the dam's elements have been injured (light damage on the neck). It is notable that the stiffness of elements is decreased by reducing the Young modulus of them.

(ii) Scenario 2. Toe: stiffness of a small region $(0.35 \%$ damage) in the toe of the dam is decreased to $10 \%$ of its initial value in the intact condition, as shown in Figure 12(b) (light damage in the toe).

(iii) Scenario 3. Toe and neck together: stiffness of a small number of elements of the toe as well as the neck of the dam ( $0.6 \%$ damage) is reduced $90 \%$, as illustrated in Figure 12(c) (light damage in the toe and neck).

(iv) Scenario 4. Lift joints: stiffness of a small number of elements in the lift joints $(0.2 \%$ damage $)$ are decreased to $10 \%$ of their initial value in the intact condition as shown in Figure 12(d).

5.3. Results. Figure 13 illustrates the residual mode shape curvature as well as wavelet coefficients corresponding to different scales vs. the dam height for the first scenario. As mentioned before, since the third mode shape was obtained with a bias with respect to its real vector, this mode shape was not efficient in damage detection scheme. Therefore, results are shown only for the first and second mode shapes.

Results of CWT on the residual vector of curvature between the healthy and damaged dam for the first and second mode shape are shown in Figures 13(a) and 13(b), respectively. It is clear that at about $70 \%$ of the dam's total height, a mutation in the wavelet coefficients is revealed. In fact, this jump in the scalogram of wavelet coefficients occurs because of the existing damage in this location.

Figure 14 illustrates the result of damage detection for the second scenario. As it can be seen, the absolute value of wavelet coefficients is higher at the base of the dam as compared to other locations. Therefore, these spikes in the CWT at the base of the dam represent the location of the damage. Also, both mode shapes are applicable for identifying the location of the damage in this scenario.

Figure 15 presents the results of damage detection when the damage occurs in the toe and the neck of the dam simultaneously. Although the result of CWT on the first mode shape had not significant effect in detecting the damage in the toe of the dam, a jump in scalogram is observed in the height corresponds to the dam's neck. Moreover, for the second mode, by applying the CWT on the residual mode shape curvature of the healthy and defective structure, there are two jumps in the absolute values of CWT where the damage has occurred. It can be concluded that the second mode shape is much sensitive to 

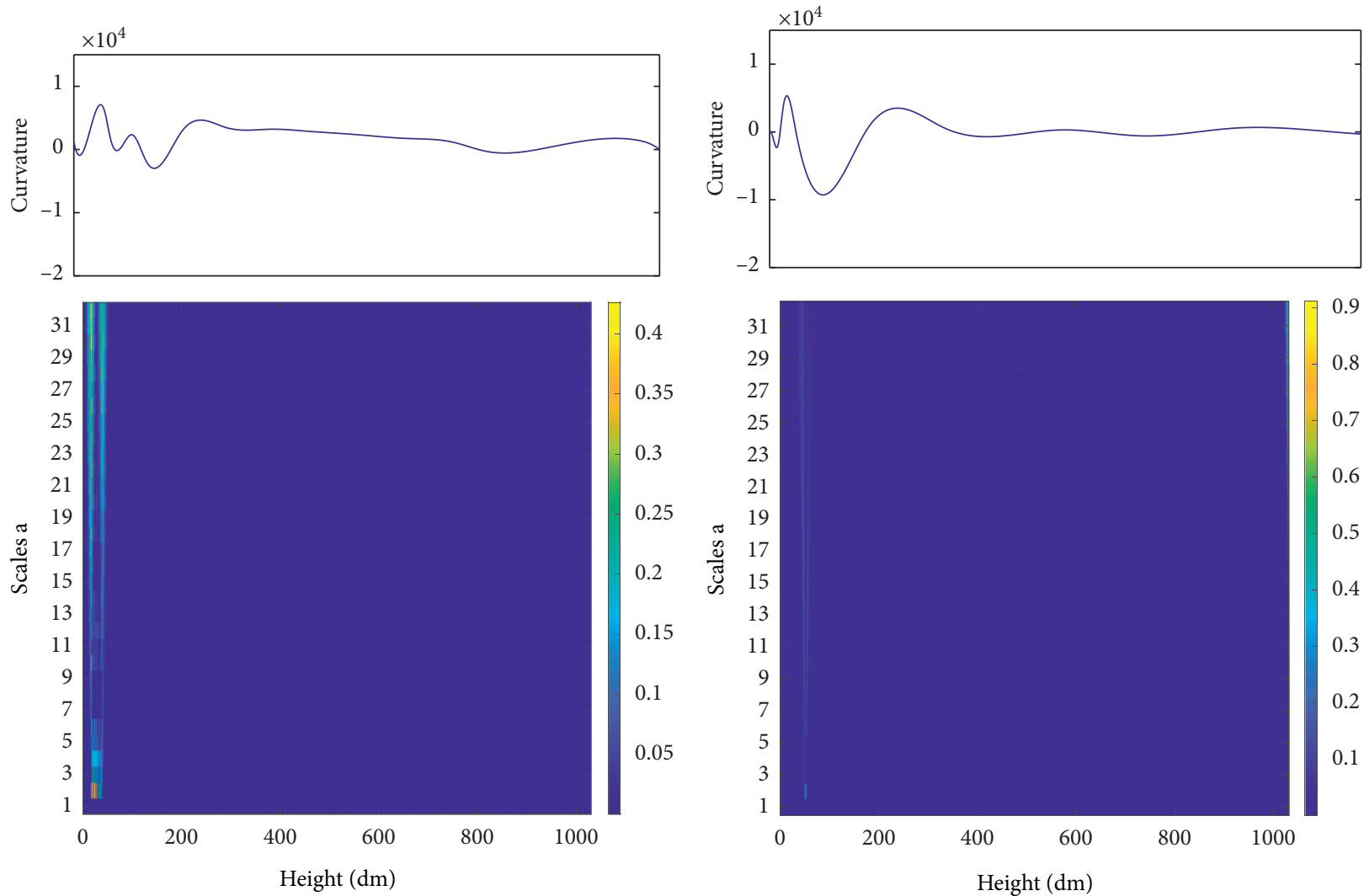

(a)

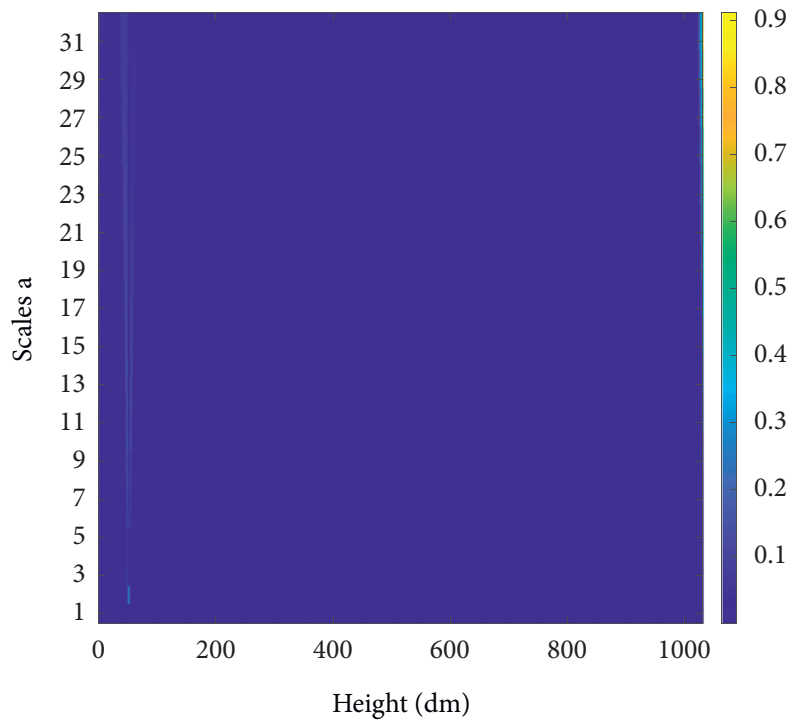

(b)

FIGURE 14: Residual value of mode-shape curvature and corresponding scalogram for the second scenario (damage in the toe). (a) First mode. (b) Second mode.

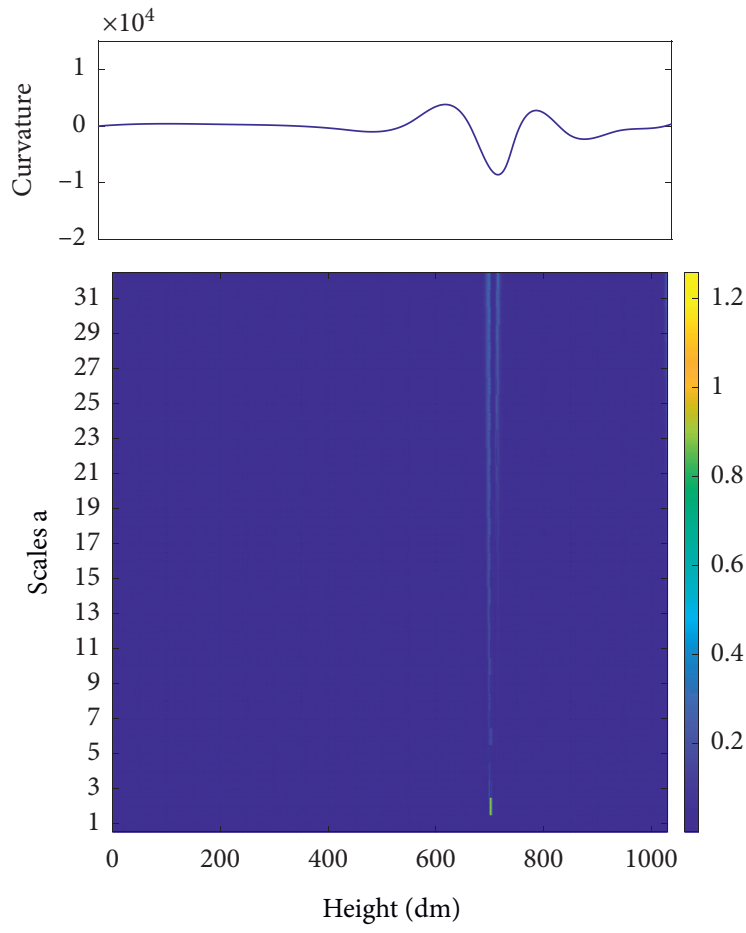

(a)
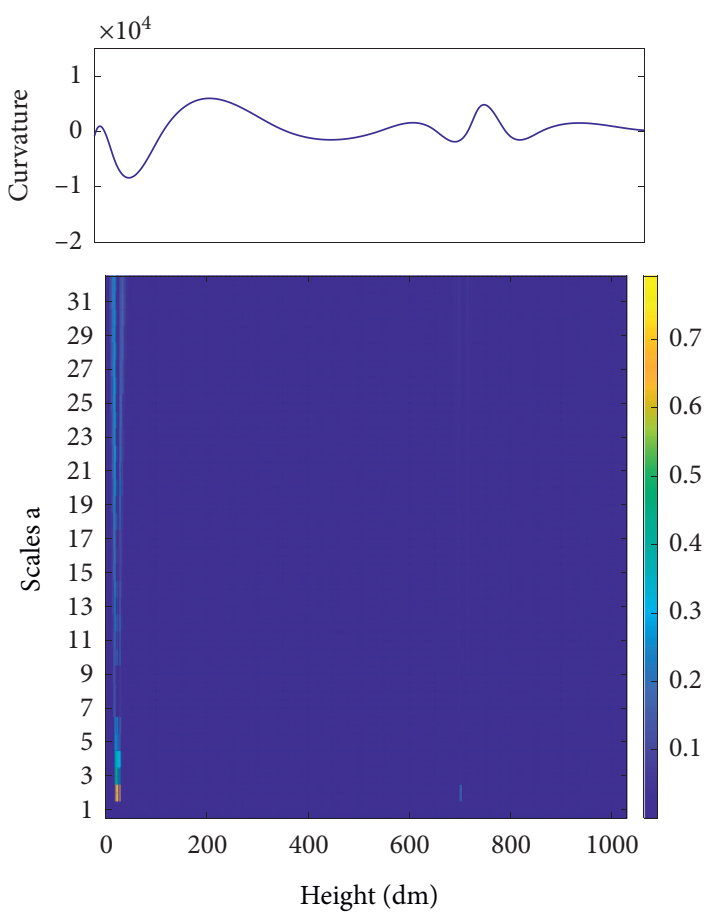

(b)

FIGURE 15: Residual value of mode-shape curvature and corresponding scalogram for the third scenario (damage in the toe and the neck). (a) First mode. (b) Second mode. 


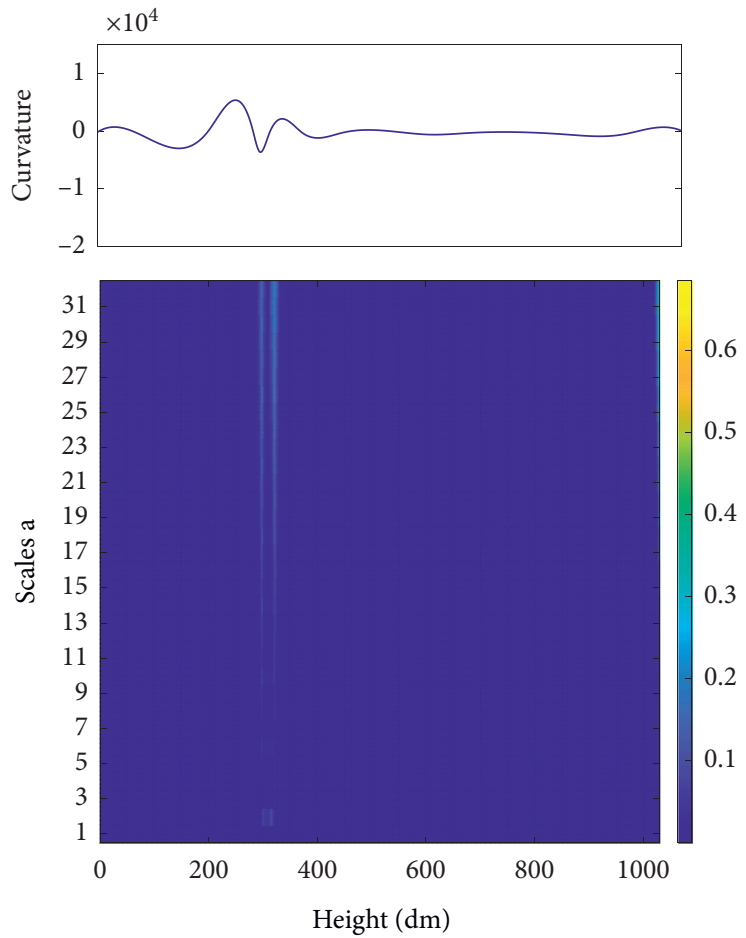

(a)

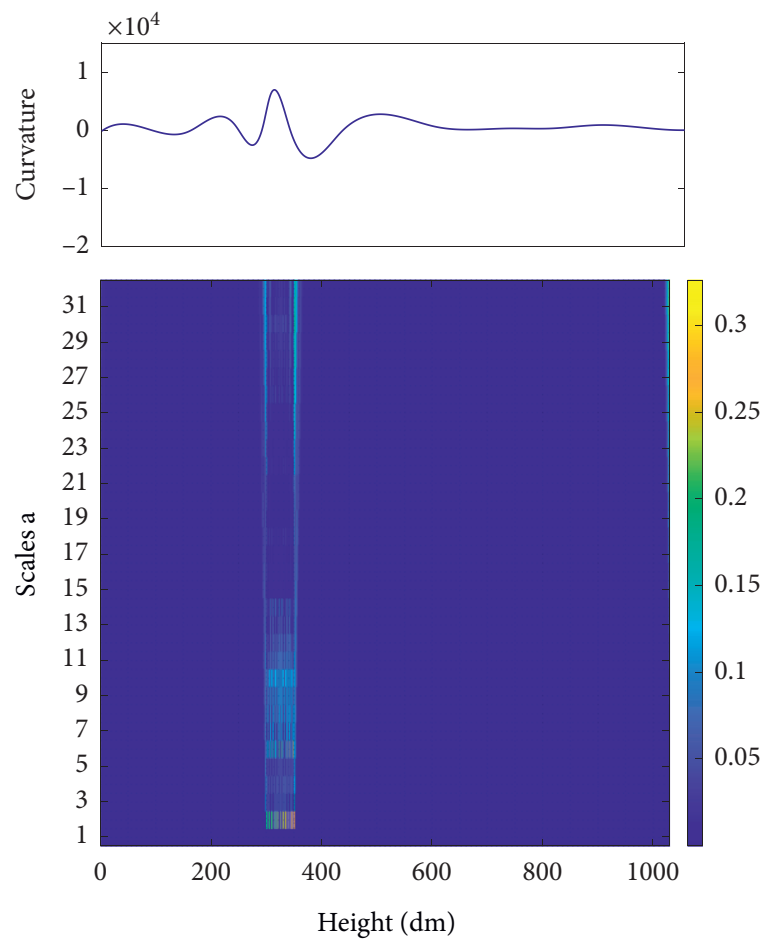

(b)

FIGURE 16: Residual value of mode-shape curvature and corresponding scalogram for the fourth scenario (damage in the lift nodes elements). (a) First mode. (b) Second mode.

the damage scenario where multiple instances of damage have occurred in the body of the dam.

Finally, Figure 16 shows the result of damage detection for the fourth damage scenario where slight damage was created in the elements located in the lift joints. As it can be seen, a sharp jump is revealed at the height where the damage has occurred. Moreover, it is evident that both mode shapes (first and second modes) were efficient for detecting the location of the damage.

\section{Conclusions}

This study presents a system identification-based damage detection procedure for the purpose of identifying the damage that occurred in the body of dam structures. An optimization algorithm based on minimizing the nondiagonal entries of the MAC matrix is applied to estimate the best location of sensors, which leads to the best possible precision of damage detection procedure. The proposed method requires to implement only six sensors along the height of dam. The conducted method present in this study is founded on identifying the modal properties of the structure under ambient excitation. To simulate the practical condition (effect of arbitrary noise), the structural response obtained through $\mathrm{FE}$ analysis was polluted with $10 \%$ noise. By applying the random decrement technique, the free vibration of the dam was identified at each sensor location. Then, the dynamic characteristics of the dam are detected using the Hilbert-Huang method. The mode shapes of the structure were calculated based on the method proposed by
Yang et al. [43]. Four potential damage scenarios were created, and mode shapes are obtained for both healthy and defective structures.

Eventually, by implementing CWT to the residual vector of the mode shape's curvature of the fully operational and damaged structures, the wavelet coefficients in terms of the scale parameter were calculated along the height of the dam. This research illustrated that the first, second, and fourth damage scenarios were easily detectable from the first two mode shapes. In addition, the damage scenario no. 3 was detected by only the second mode shape, and the first mode shape did not reveal the damage in the toe of the dam. Although the third mode shape of the structure was also identified, it did not contribute in detecting the location of the damage due to the high level of discrepancy compared to the ideal mode shape. The results show a promising and accurate framework in detecting the damage location even when the damage occurred in multiple locations. Also, regarding the high level of importance of such structures, it is recommended that the procedure presented in this study be accompanied by a visual inspection of experienced structural engineers. Finally, the authors propose additional research conducted by applying further experimental tests for dams with various size characteristics and element configurations.

\section{Data Availability}

All data are included within the article. 


\section{Conflicts of Interest}

The authors declare that they have no conflicts of interest regarding the publication of this paper.

\section{References}

[1] P. Bukenya, P. Moyo, H. Beushausen, and C. Oosthuizen, "Health monitoring of concrete dams: a literature review," Journal of Civil Structural Health Monitoring, vol. 4, no. 4, pp. 235-244, 2014.

[2] R. Karami-Mohammadi, M. Mirtaheri, M. Salkhordeh, and M. A. Hariri-Ardebili, "Vibration anatomy and damage detection in power transmission towers with limited sensors," Sensors, vol. 20, no. 6, p. 1731, 2020.

[3] J. M. W. Brownjohn, "Structural health monitoring of civil infrastructure," Philosophical Transactions of the Royal Society A: Mathematical, Physical and Engineering Sciences, vol. 365, no. 1851, pp. 589-622, 2007.

[4] W. J. Graham, A Procedure for Estimating Loss of Life Caused by Dam Failure, US Department of the Interior, Bureau of Reclamation, Washington, DC, USA, 1999.

[5] T. P. Rich, "Lessons in social responsibility from the Austin dam failure," International Journal of Engineering Education, vol. 22 , no. 6, p. 1287, 2006.

[6] P. C. Chang, A. Flatau, and S. C. Liu, "Review paper: health monitoring of civil infrastructure," Structural Health Monitoring: An International Journal, vol. 2, no. 3, pp. 257-267, 2003.

[7] R. Karami-Mohammadi, M. Mirtaheri, M. Salkhordeh, and M. A. Hariri-Ardebili, "A cost-effective neural network-based damage detection procedure for cylindrical equipment," Advances in Mechanical Engineering, vol. 11, no. 7, 2019.

[8] S. O. Sajedi and X. Liang, "A data-driven framework for near real-time and robust damage diagnosis of building structures," Structural Control and Health Monitoring, vol. 27, no. 3, p. e2488, 2020.

[9] H. Cui, X. Xu, W. Peng, Z. Zhou, and M. Hong, "A damage detection method based on strain modes for structures under ambient excitation," Measurement, vol. 125, pp. 438-446, 2018.

[10] M. Montazer and S. M. Seyedpoor, "A new flexibility based damage index for damage detection of truss structures," Shock and Vibration, vol. 2014, Article ID 460692, , 2014.

[11] E. T. Lee and H. C. Eun, "Disassembling-based structural damage detection using static measurement data," Shock and Vibration, vol. 2019, Article ID 6073828, , 2019.

[12] B. D. Ding, D. S. Feng, H. L. Lv, and X. Li, "Damage detection in grid structures using limited modal test data," Mathematical Problems in Engineering, vol. 2017, Article ID 1089645, , 2017.

[13] J. Liu, W. D. Zhu, P. G. Charalambides, Y. M. Shao, Y. F. Xu, and X. M. Fang, "A dynamic model of a cantilever beam with a closed, embedded horizontal crack including local flexibilities at crack tips," Journal of Sound and Vibration, vol. 382, pp. 274-290, 2016.

[14] L. A. Montejo, "Signal processing based damage detection in structures subjected to random excitations," Structural Engineering and Mechanics, vol. 40, no. 6, pp. 745-762, 2011.

[15] Q. Pu, Y. Hong, L. Chen, S. Yang, and X. Xu, "Model updating-based damage detection of a concrete beam utilizing experimental damped frequency response functions," $A d-$ vances in Structural Engineering, vol. 22, no. 4, pp. 935-947, 2019.
[16] K. Worden, G. Manson, and N. R. J. Fieller, "Damage detection using outlier analysis," Journal of Sound and Vibration, vol. 229, no. 3, pp. 647-667, 2000.

[17] R. Ditommaso, F. C. Ponzo, and G. Auletta, "Damage detection on framed structures: modal curvature evaluation using stockwell transform under seismic excitation," Earthquake Engineering and Engineering Vibration, vol. 14, no. 2, pp. 265-274, 2015.

[18] J. Zhang, S. L. Guo, Z. S. Wu, and Q. Q. Zhang, "Structural identification and damage detection through long-gauge strain measurements," Engineering Structures, vol. 99, pp. 173-183, 2015.

[19] O. Yazdanpanah, S. M. Seyedpoor, and H. A. Bengar, "A new damage detection indicator for beams based on mode shape data," Structural Engineering and Mechanics, vol. 53, no. 4, pp. 725-744, 2015.

[20] E. Figueiredo, G. Park, C. R. Farrar, K. Worden, and J. Figueiras, "Machine learning algorithms for damage detection under operational and environmental variability," Structural Health Monitoring, vol. 10, no. 6, pp. 559-572, 2011.

[21] R. Ghiasi, P. Torkzadeh, and M. Noori, "A machine-learning approach for structural damage detection using least square support vector machine based on a new combinational kernel function," Structural Health Monitoring: An International Journal, vol. 15, no. 3, pp. 302-316, 2016.

[22] P. Ghannadi and S. S. Kourehli, "Structural damage detection based on MAC flexibility and frequency using moth-flame algorithm," Structural Engineering and Mechanics, vol. 70, no. 6, pp. 649-659, 2019.

[23] D. H. Nguyen, T. T. Bui, G. De Roeck, and M. A. Wahab, "Damage detection in Ca-Non Bridge using transmissibility and artificial neural networks," Structural Engineering and Mechanics, vol. 71, pp. 175-183, 2019.

[24] B. S. Wang and Z. C. He, "Crack detection of arch dam using statistical neural network based on the reductions of natural frequencies," Journal of Sound and Vibration, vol. 302, no. 4-5, pp. 1037-1047, 2007.

[25] T. Turker, A. Bayraktar, and B. Sevim, "Vibration based damage identification of concrete arch dams by finite element model updating," Computers and Concrete, vol. 13, no. 2, pp. 209-220, 2014.

[26] S. Pirboudaghi, R. Tarinejad, and M. T. Alami, "Damage detection based on system identification of concrete dams using an extended finite element-wavelet transform coupled procedure," Journal of Vibration and Control, vol. 24, no. 18, pp. 4226-4246, 2018.

[27] B. Sevim, A. C. Altunisik, and A. Bayraktar, "Structural identification of concrete arch dams by ambient vibration tests," Advances in Concrete Construction, vol. 1, no. 3, p. 227, 2013.

[28] E. M. Bianchi and E. R. Bremen, "July. Health monitoring of arch dams recent developments," in Proceedings of the International Workshop on the Present and Future in Heath Monitoring, Bauhaus University, Weimar, Germany, September 2000.

[29] J. Mata, "Interpretation of concrete dam behaviour with artificial neural network and multiple linear regression models," Engineering Structures, vol. 33, no. 3, pp. 903-910, 2011.

[30] S. M. Seyed-Kolbadi, M. A. Hariri-Ardebili, M. Mirtaheri, and F. Pourkamali-Anaraki, "Instrumented health monitoring of an earth dam," Infrastructures, vol. 5, no. 3, p. 26, 2020.

[31] M. S. Saidi, M. Rismanian, M. Monjezi, M. Zendehbad, and S. Fatehiboroujeni, "Comparison between Lagrangian and 
Eulerian approaches in predicting motion of micron-sized particles in laminar flows," Atmospheric Environment, vol. 89, pp. 199-206, 2014.

[32] K. C. Park, C. A. Felippa, and J. A. DeRuntz, "Stabilization of staggered solution procedures for fluid-structure interaction analysis," Computational Methods for Fluid-Structure Interaction Problems, vol. 26, no. 94-124, p. 51, 1977.

[33] M. Hariri-Ardebili and V. Saouma, "Impact of near-fault vs. far-field ground motions on the seismic response of an arch dam with respect to foundation type," Dam Engineering, vol. 24, no. 1, pp. 19-52, 2014.

[34] M. A. Hariri-Ardebili, S. M. Seyed-Kolbadi, and H. Mirzabozorg, "A smeared crack model for seismic failure analysis of concrete gravity dams considering fracture energy effects," Structural Engineering and Mechanics, vol. 48, no. 1, pp. 17-39, 2013.

[35] A. K. Chopra, "Earthquake response analysis of concrete dams," in Advanced Dam Engineering for Design, Construction, and Rehabilitation, R. B. Jansen, Ed., Springer, Berlin, Germany, 1988.

[36] S. S. Bhattacharjee and P. Léger, "Application of NLFM models to predict cracking in concrete gravity dams," Journal of Structural Engineering, vol. 120, no. 4, pp. 1255-1271, 1994.

[37] M. A. Hariri-Ardebili and S. M. Seyed-Kolbadi, "Seismic cracking and instability of concrete dams: smeared crack approach," Engineering Failure Analysis, vol. 52, pp. 45-60, 2015.

[38] M. A. Hariri-Ardebili and V. E. Saouma, "Collapse fragility curves for concrete dams: comprehensive study," Journal of Structural Engineering, vol. 142, no. 10, Article ID 04016075, 2016.

[39] ABAQUS 2007, Abaqus Theory Manual, ABAQUS, Inc., Providence, RI, USA, 7th edition, 2007.

[40] J. Morlet, G. Arens, E. Fourgeau, and D. Glard, "Wave propagation and sampling theory-Part I: complex signal and scattering in multilayered media," Geophysics, vol. 47, no. 2, pp. 203-221, 1982.

[41] A. Grossmann, J. Morlet, and T. Paul, "Transforms associated to square integrable group representations. I. General results," Journal of Mathematical Physics, vol. 26, no. 10, pp. 24732479, 1985.

[42] D. Popov, A. Gapochkin, and A. Nekrasov, "An algorithm of daubechies wavelet transform in the final field when processing speech signals," Electronics, vol. 7, no. 7, p. 120, 2018.

[43] J. N. Yang, Y. Lei, S. Pan, and N. Huang, "System identification of linear structures based on Hilbert-Huang spectral analysis. part 1: normal modes," Earthquake Engineering \& Structural Dynamics, vol. 32, no. 9, pp. 1443-1467, 2003.

[44] MATLAB, MATLAB Version 9.1 (R2016b), The MathWorks Inc., Natick, MA, USA, 2016.

[45] M. Chang and S. N. Pakzad, "Optimal sensor placement for modal identification of bridge systems considering number of sensing nodes," Journal of Bridge Engineering, vol. 19, no. 6, Article ID 4014019, 2014.

[46] R. Morsy, H. Marzouk, X. Gu, and A. Elshafey, "Use of the random decrement technique for nondestructive detection of damage to beams," Materials and Structures, vol. 49, no. 11, pp. 4719-4727, 2016.

[47] Y.-Z. Lin, Z.-H. Nie, and H.-W. Ma, "Structural damage detection with automatic feature-extraction through deep learning," Computer-Aided Civil and Infrastructure Engineering, vol. 32, no. 12, pp. 1025-1046, 2017.

[48] S. McKinley and M. Levine, "Cubic spline interpolation," College of the Redwoods, vol. 45, pp. 1049-1060, 1998.
[49] R. Karami Mohammadi, M. Khalaj, and M. Mohammadgholiha, "Curvature method to detect location and depth of a plastic zone in frame members during an earthquake," Numerical Methods in Civil Engineering, vol. 3, no. 2, pp. 1-12, 2018. 